\title{
Investigations towards the synthesis of a CD-steroid intermediate
}

\author{
D K BANERJEE, T R KASTURI*, R SAI BABA and A SARKAR \\ Department of Organic Chemistry, Indian Institute of Science, Bangalore 560012, India \\ MS received 3 May 1985; revised 24 June 1985

\begin{abstract}
The development of a new synthesis of $2,6,7,7 \mathrm{a}$-tetrahydro- $\beta$-hydroxy-4-formyl$7 \mathrm{a}$-methylindene was undertaken involving the preparation of $2,6,7,7 \mathrm{a}$-tetra-hydro- $\beta$ hydroxy-4-methoxymethyl-7a-methylindene because of the erratic yield in the last oxidation step of the reported synthesis of the former compound. Although various attempts to prepare the latter were not successful, interesting rearrangement products, the dienone, 5,6,7,7atetrahydro-4,7a-dimethyl-5H-indene-1,5-dione and the tricyclic keto alcohol, 2,6-diketo-3methyltricyclo( $5,2,1,0)$ decan-8-ol, were obtained, the structures of which have been proved by spectral data. Mechanisms for the formation of these products have been proposed.
\end{abstract}

Keywords. Methylindene; synthesis; spectral data; dienone; tricyclic keto alcohol.

\section{Introduction}

In the synthesis of 2,6,7,7a-tetrahydro-1 $\beta$-hydroxy-4-formyl-7a-methylindene (1a) (Banerjee et al 1976) and its optically active form (Banerjee $e t$ al 1983), considered to be an important synthon for the total synthesis of steroids, inconsistent yields were encountered in the last step involving oxidation of $1 \mathrm{~b}$ to $1 \mathrm{a}$ by selenium dioxide. This prompted us to undertake the preparation of the methoxy compound (1d) that might be converted to $\underline{1 \mathrm{a}}$ via the hydroxy compound (1c).

\section{Results and discussion}

For this purpose, the methoxyaminoketone (2a), the diaminoketone (2d) and the ethoxyaminoketone ( $2 \mathrm{~b})$ were prepared, as described below, and subjected to the annelation reaction with 2-methylcyclopentan-1,3-dione ( 2 ) under various conditions.

For the preparation of the first compound, 2-methoxyethyl bromide (Tallman 1934) was added to sodium acetylide, prepared by bubbling dry acetylene through sodamide in liquid ammonia, to get 4-methoxybut-1-yne (3) in $66 \%$ yield. Mannich reaction with the compound ( 3 ), formaldehyde and diethylamine gave the methoxydiethylamine (4), which was hydrated with mercuric sulphate and aq. $\mathrm{H}_{2} \mathrm{SO}_{4}$ to give the methoxyaminoketone $(2 \mathrm{a})$ in $25 \%$ yield. The structural assignment was supported by spectral data. The regioselectivity in the hydration reaction was presumably due to the following reasons. In the acetylenic amine (4), the C-3 is electron-deficient because of the relatively stronger inductive effect of the nitrogen of the aminomethylene compared to that of the oxygen of the methoxymethylene, the latter being separated by one extra

- To whom all correspondence should be addressed. 